\title{
Association of Streptococcus with Guttate Psoriasis: An Observational Study at Two Tertiary Care Hospitals in Dhaka
}

\author{
Hossain $\mathrm{A}^{1}$, Ali $\mathrm{E}^{2}$, Bhuian $\mathrm{I}^{3}$, Hossain $\mathrm{MS}^{4}$, Bisas $\mathrm{HS}^{5}$
}

\begin{abstract}
Background: Psoriasis is multifactorial in origin. Streptococcal infection, sore throat has been claimed to be an infectious cause. Objective: The purpose of the present study was to observe the association of Streptococcus with guttate psoriasis. Methodology: This was an observational case-control study which was conducted in the Department of Dermatology \& Venereology at Bangabandhu Sheikh Mujib Medical University (BSMMU), \& Shaheed Suhrawardy Medical College hospital (ShSMCH) in Dhaka city of Bangladesh during the period of February 2012 to October 2012. Patients clinically and histopathologically diagnosed as psoriasis were selected as case group and patients with skin diseases other than psoriasis were selected as control group. Results: A total of 115 patients were included in this study of which 64 patients were in case group and the rest 51 patients were designated as control group. The mean age was $30.73 \pm 14.69$ years and $26.47 \pm 12.64$ years in cases and control groups respectively ( $>0.05)$. About $66.6 \%$ patients gave a positive history of sore throat. ASO titer was raised $(>200 \mathrm{IU} / \mathrm{ml})$ in $25(83.3 \%)$ patients of guttate psoriasis and $5(23.8 \%)$ in patients of their non-psoriatic controls $(\mathrm{p}<0.05)$. Streptococcus pyogenes was found in $9(30.0 \%)$ patients of case group and only $2(9.5 \%)$ patients were found in their control group. Conclusion: Streptococcal throat infections are associated with guttate psoriasis patients. [J Shaheed Suhrawardy Med Coll, 2013;5(2):91-94]
\end{abstract}

Keywords: Streptococcal throat infections, throat infections, guttate psoriasis

Received: March 2013; Revised: April 2013; Accepted: May 2013

\section{Introduction}

Psoriasis is a common, chronic, disfiguring, inflammatory and proliferative condition of the skin $^{1}$. However its prevalence varies from $0.1 \%$ to $11.8 \%{ }^{2-3}$. The etiopathogenesis of the disease is still largely unknown; however, studies indicate that it is caused by an interaction of multiple genetic components and environmental factors including $\beta$-haemolytic Streptococci ${ }^{4}$.

There is evidence that an immunologic mechanism is involved in the triggering of psoriasis by Streptococcal infections. Stimulation of $\mathrm{T}$ cells by Streptococcal superantigen causes release of immune cytokines such as IL-2, which are important in the pathogenesis of psoriasis ${ }^{5-7}$.
Increased numbers of interferon $\beta$ producing Th1 cells with specificity for group A Streptococcal antigens have been also detected in the skin lesions of both guttate psoriasis (GP) and chronic plaque psoriasis (CPP) ${ }^{8}$.

It is possible that Streptococci contain antigenic substances recognized by psoriatic $\mathrm{T}$ cells. Furthermore Baker et $\mathrm{al}^{9}$ have reported the presence of Streptococcal antigen specific $\mathrm{T}$ cells in guttate psoriasis lesions. Swerlick et $\mathrm{al}^{10}$ have demonstrated cross-reactivity between epidermal keratins and Streptococci. Villeda et al ${ }^{11}$ confirmed the autoimmune components in guttate psoriasis, due to cross reactions between skin and Streptococcal antigens. There is a strong association between prior infection with Streptococcus

1. Dr. Md. Akram Hossain, Assistant Professor, Department of Dermatology \& Venereology, Sir Salimullah Medical College \& Mitford Hospital, Dhaka.

2. Prof. Dr. Md. Eakub Ali, Professor, Department of Dermatology \& Venereology, Banghabandhu Sheikh Mujib Medical University, Dhaka

3. Dr. Ishrat Bhuiyan, Assistant Professor, Department of Dermatology \& Venereology, Shaheed Suhrawardy Medical College, Dhaka

4. Dr. Md. Shahadat Hossain, Associate Professor, Department of Dermatology \& Venereology, Shaheed Suhrawardy Medical College, Dhaka

5. Dr. Biswas Shahin, Medical Officer, Department of Dermatology \& Venereology, Banghabandhu Sheikh Mujib Medical University, Dhaka

\section{Correspondence}

Dr. Md. Akram Hossain, Assistant Professor, Department of Dermatology \& Venereology, Sir Salimullah Medical College \& Mitford Hospital, Dhaka., Bangladesh; Cell No: +8801553534962; Email: akramhk48@yahoo.com

Funding Source: Self funding and institutions providing some technical support.

Conflict of interest: None

Contributions by authors: MAH \& MEA involved from protocol preparation to manuscriptive writing, IB, MSH, BS contributed to data analysis and preparation of manuscript as well as revised the manuscript 
pyogenes ( $\beta$-haemolytic Streptococcus) and psoriasis, which was proved by a history of an acute sore throat 1 to 3 weeks before the eruption and bacteriological and serological evidence of recent Streptococcal infection ${ }^{12}$. Currently there is no cure for psoriasis and treatment options produce variable response, in part, because disease pathogenesis is not completely understood ${ }^{13}$. Moreover, treatment of psoriasis and maintenance of its remission is still challenging.

In Bangladesh several studies were done on psoriasis and no data about association between Streptococcal throat infection and psoriasis is available so far. Considering the co-morbidities of psoriasis patients, it might be justifiable to find out this treatable or modifiable event that provoke the initiation or exacerbation or maintenance of psoriatic disease process in order to control that one. The purpose of the present study was to observe the association of Streptococcus with guttate psoriasis.

\section{Methodology}

This was an observational case-control study which was conducted in the Department of Dermatology \& Venereology at Bangabandhu Sheikh Mujib Medical University (BSMMU), and Shaheed Suhrawardy Medical College Hospital (ShSMCH) in Dhaka during the period of February 2012 to October 2012 for a period of 8(eight) months. Patients suggestive of psoriasis and non psoriasis attending the inpatient and outpatient department of BSMMU \& ShSMCH, after verbal consent and fulfil the inclusion and exclusion criteria who were confirmed histopathologically and receiving the both swabs culture and ASO titre reports were included as study population. Histopathological confirmed psoriatic patients were taken as case group and non psoriatic patients were taken as control group. Purposive type of non-probability sampling technique was followed in this study. During selecting controls, ages and both sexes were matched. Throat swabs was taken and pathogenic organism was identified by gross colony morphology and types of hemolysis on culture media. $\beta$-hemolysis indicated growth of Streptococcus pyogens. Antistreptolysin O titre (ASO titre) was measured and titre $200 \mathrm{IU} / \mathrm{ml}$ or greater was considered as evidence of recent Streptococcal infections. Patients who were on systemic anti-psoriatic drugs and/or taking systemic antibiotics and minimum within previous 15 days from interviewing were excluded from this study. Detail personal and family history of skin disease, age of onset of 1 st psoriasis, the presence or absence of sore throat, date of last attack of sore throat, frequency of sore throat per year and other infections, psoriatic lesions exacerbate /deteriorate suddenly after sore throat and any history of rheumatic fever or carditis, AGN (nephritis) and erythema nodusum (EN) were recorded in a predesigned data sheet. Statistical analysis was done by using SPSS program (version 16). Statistical significance was set at 5\% level and confidence interval at $95 \%$ level.

\section{Results}

A total number of 64 patients were recruited as case group of which 15 patients were acute guttate psoriasis, 15 patients were guttate flare of chronic plaque psoriasis, 7 patients were deterioration of chronic plaque psoriasis, 26 patients were chronic plaque psoriasis and 1 patient was pustular psoriasis; furthermore a total number of 51 patinets were recruited in control group.

Table I: Distribution of respondents according to age.

\begin{tabular}{lccc}
\hline Age group & Case & Control & P value \\
\hline $0-9$ & $3(4.76 \%)$ & $3(5.9 \%)$ & \\
$10-19$ & $13(20.6 \%)$ & $9(17.6 \%)$ & \\
$20-29$ & $15(22.2 \%)$ & $22(43.1 \%)$ & \\
$30-39$ & $12(19.0 \%)$ & $9(17.6 \%)$ & \\
$40-49$ & $14(22.2 \%)$ & $4(7.84 \%)$ & $>0.05^{\text {ns }}$ \\
$50-59$ & $4(6.3 \%)$ & $3(5.9 \%)$ & \\
$>60$ & $3(4.8 \%)$ & $1(1.96 \%)$ & \\
Total & $\mathbf{6 4}(\mathbf{1 0 0 \% )}$ & $\mathbf{5 1}(\mathbf{1 0 0 \% )}$ & \\
\hline Mean \pm SD & $30.73 \pm 14.69$ & $26.47 \pm 12.64$ & \\
\hline
\end{tabular}

${ }^{*} p$ value obtained from Student test, $n s=$ Non significant

Among the controls 11 patients were selected for acute guttate psoriasis, 10 patients were for guttate flare of chronic plaque psoriasis, 4 patients were for deterioration of choric plaque psoriasis, 25 patients were for chronic plaque type psoriasis and 1 patient was for pustular psoriasis. In this study of respondents was 57 years in case and 56 years in control group. Mean age was $30.73 \pm$ 14.69 years (age range 8 to $65 \mathrm{yrs}$ ) in cases and $26.47 \pm$ 12.64 years (age range 4 to $60 \mathrm{yrs}$ ) in control. There was no significant difference between two groups. (Table I).

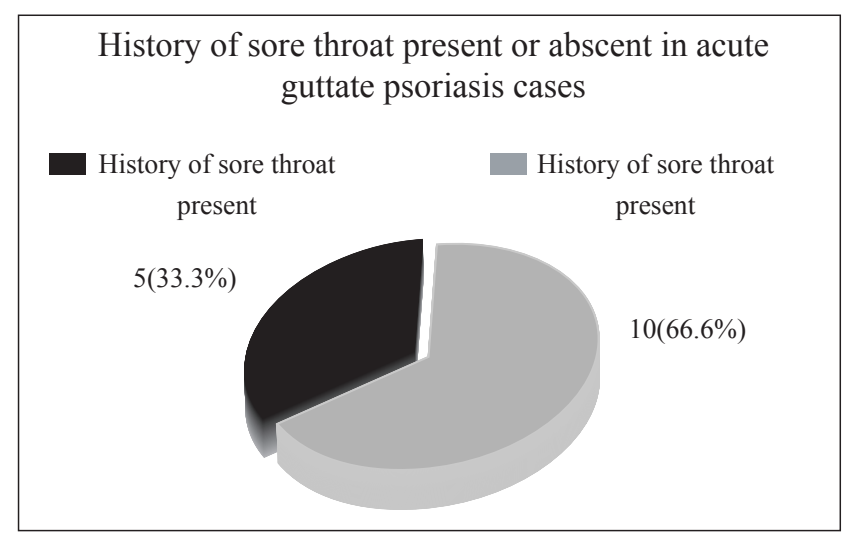

Figure 1: Distribution of respondents by history of sore throat before the appearance of acute guttate psoriasis.

Comparison of ASO titer in case and control groups is shown in the table II. ASO titer was raised in $65.6 \%$ psoriasis patients and $19.6 \%$ non psoriasis controls. Majority of cases of total guttate psoriasis (83.3\%) was presented with raised ASO titer in blood report versus $23.8 \%$ in respective controls (Table III) and chronic plaque 
psoriasis stood on next. There was significant difference in ASO titer status between psoriasis and non psoriatic groups (P-value $<0.05$ ) (Table II).

Table II: ASO titer value $(>200$ or $<200)$ in two groups (psoriasis and non psoriatic patient)

\begin{tabular}{lccccc}
\hline Type of psoriasis & \multicolumn{2}{c}{ Case $(\mathbf{n}=\mathbf{6 4})$} & \multicolumn{2}{c}{ Control (n=51) } & \multirow{2}{*}{ P value } \\
\cline { 2 - 5 } & $\begin{array}{c}\text { Raised } \\
(>200 \mathrm{IU} / \mathrm{ml})\end{array}$ & $\begin{array}{c}\text { Normal } \\
(<200 \mathrm{IU} / \mathrm{ml})\end{array}$ & $\begin{array}{c}\text { Raised } \\
(>200 \mathrm{IU} / \mathrm{ml})\end{array}$ & $\begin{array}{c}\text { Normal } \\
(<200 \mathrm{IU} / \mathrm{ml})\end{array}$ & \\
\hline Acute guttate psoriasis & $13(86.6 \%)$ & 2 & $3(27.2 \%)$ & 8 & $<0.05^{*}$ \\
Guttate flare of CPS & $12(80.0 \%)$ & 3 & $2(20 \%)$ & 8 & \\
CPS & $12(46.1 \%)$ & 14 & $4(16 \%)$ & 21 & \\
Deterioration of CPS & $5(71.4 \%)$ & 2 & $1(33.3 \%)$ & 3 & \\
Pustular psoriasis & 0 & 1 & 0 & 1 & \\
Total & $\mathbf{4 2 ( 6 5 . 6 \% )}$ & $\mathbf{2 2}$ & $\mathbf{1 0}(\mathbf{1 9 . 6 \% )}$ & $\mathbf{4 1}$ & \\
\hline
\end{tabular}

*P value significant; chronic plaque Psoriasis $=\mathrm{CPS}$

ASO titer was raised $(>200 \mathrm{IU} / \mathrm{ml})$ in $25(83.3 \%)$ patients of guttate psoriasis and $5(23.8 \%)$ patients of their nonpsoriatic controls. The difference of ASO titer status between this two groups was significant $(\mathrm{P}$-value $<0.05)$ (Table III).

Table III: Comparison of ASO titer status in guttate psoriasis and respective control

\begin{tabular}{lcccc}
\hline ASO titer status & Case Group & Control Group & Total & P value \\
\hline Raised $(>200 \mathrm{IU} / \mathrm{ml})$ & $25(83.3 \%)$ & $5(23.8 \%)$ & 30 & \\
Normal $(<200 \mathrm{IU} / \mathrm{ml})$ & $5(16.7 \%)$ & $16(76.2 \%)$ & 21 & \\
Total & $30(\mathbf{1 0 0 . 0} \%)$ & $\mathbf{2 1 ( 1 0 0 . 0 \% )}$ & $\mathbf{5 1 ( 1 0 0 . 0 \% )}$ & \\
\hline
\end{tabular}

*P value significant

Table IV shows the throat swab culture results in different types of psoriasis and respective controls. In case of throat swab culture, normal flora 21(70\%) was found in guttate psoriasis group and $19(90.5 \%)$ was found in their control group and streptococcus pyogenes $9(30.0 \%)$ was found in case of guttate psoriasis group and $2(9.5 \%)$ was found in control group (Table V).

Table IV: Results Of Throat Swab Culture In Different Types Of Psoriasis And Their Control

\begin{tabular}{|c|c|c|c|c|c|c|}
\hline \multirow[t]{2}{*}{ Type of psoriasis } & \multicolumn{3}{|c|}{ Case $(n=64)$} & \multicolumn{3}{|c|}{ Control (n=51) } \\
\hline & 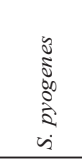 & 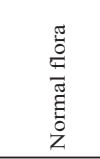 & 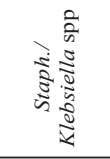 & 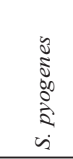 & $\begin{array}{l}\frac{\pi}{0} \\
\stackrel{0}{0} \\
\overparen{\Xi} \\
\vdots \\
Z\end{array}$ & 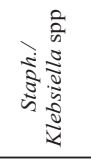 \\
\hline AGP & $5(33.3)$ & $10(66.6)$ & 0 & $1(9.1)$ & $10(90.9)$ & 0 \\
\hline Guttate flare of CPP & $4(26.6)$ & $11(73.3)$ & 0 & $1(10)$ & $9(90)$ & 0 \\
\hline СРP & $4(15.3)$ & $21(80.7)$ & $1(3.8 \%)^{\dagger}$ & $2(8)$ & $23(92)$ & 0 \\
\hline $\begin{array}{l}\text { Deterioration of } \\
\text { CPP }\end{array}$ & $3(42.8)$ & $3(42.8)$ & $1(14.2 \%)^{*}$ & $1(25)$ & $3(75)$ & 0 \\
\hline Pustular psoriasis & 0 & $1(100)$ & 0 & 0 & 0 & $1(100.0)$ \\
\hline
\end{tabular}

$\dagger$ Klebsiella spp, †Staphylococcus aureus; $\mathrm{CPP}=$ chronic plaque Psoriasis; S. pyogenes $=$ Streptococcus pyogenes; $\mathrm{CPP}=$ chronic plaque psoriasis; Acute guttate psoriasis=AGP; Figure with parenthesis indicates percentage

\section{Discussion}

Among 64 cases 5 types of Psoriasis was detected and arranged for comparison with respective controls. About $33(51.0 \%)$ of respondents were chronic plaque psoriasis of which $26(40.6 \%)$ patients were with stable plaque psoriasis, $7(10.9 \%)$ patients were with deterioration of chronic plaque psoriasis and rest of the cases were guttate psoriasis $30(46.87 \%)$ and pustular psoriasis $1(1.5 \%)$ patient. Finaly here it hasd been considered that whether the psoriasis was guttate or not, did'nt consider new or old guttate. Similar study was conducted by Telfar et $\mathrm{al}^{12}$ with 111 patients with psoriasis, where $60 \%$ cases as chronic plaque psoriasis, $30 \%$ as acute guttate psoriasis and $10 \%$ as others psoriasis were found.

Table V: Results of throat swab culture in Guttate types of psoriasis and their non psoriatic control

\begin{tabular}{lcccc}
\hline Culture Result & $\begin{array}{c}\text { Case } \\
(\mathbf{n = 3 0})\end{array}$ & $\begin{array}{c}\text { Control } \\
(\mathbf{n}=\mathbf{2 1})\end{array}$ & Total & P value \\
\hline S. pyogenes & $9(30.0)$ & $2(9.5)$ & $11(21.6)$ & $0.1^{*}$ \\
Normal flora & $21(70.0)$ & $19(90.5)$ & $40(78.4)$ & \\
Total & $\mathbf{3 0}(\mathbf{1 0 0 . 0 )}$ & $\mathbf{2 1 ( 1 0 0 . 0 )}$ & $\mathbf{5 1 ( 1 0 0 . 0 )}$ & \\
\hline
\end{tabular}

*P value obtained from chie square test which is $>0.05$

Clinically sore throat was present in 19 (30.15\%) cases and number of attack of sore throat per year was 5 times in cases and 3 times in controls. A $66.6 \%$ patients gave a history of sore throat within 3 weeks period prior to the appearance of acute guttate psoriasis (AGP) and 64.2\% patients gave a history of sore throat within 4 weeks period prior to the appearance of guttate flare of chronic plaque psoriasis. In different study ${ }^{6}$ the history of sore throat preceding the onset of acute guttate psoriasis within 3 weeks period was $77.1 \%$ and $39 \%$. Result of this study stood between these two results.

ASO titer was raised $(>200 \mathrm{IU} / \mathrm{ml})$ in $25(83.3 \%)$ patients of guttate psoriasis and $5(23.8 \%)$ patients of their nonpsoriatic respondents. The difference of ASO titer status between this two groups was significant ( $\mathrm{P}$-value $<0.05$ ). Serologic evidence of recent Streptococcal infections indicated by raised ASO titer was found in $18(56 \%)$ of 32 patients with $31 \%$ had a history of sore throat in 1 to 3 weeks before the appearance of rash and 17(85\%) of 20 patients with AGP (Acute guttate psoriasis) in studies reported by Mukherjee et $\mathrm{al}^{14}$. In a cross sectional study with 111 patients, ASO titer was raised $43 \%$ in total, $58 \%$ in AGP and $26 \%$ in guttate exacerbation of chronic plaque psoriasis $^{12}$. Naqqash et $\mathrm{al}^{6}$ found ASO titer raised $60 \%$ in AGP versus $6.6 \%$ in control. In a prospective study, Gudjohnson et $\mathrm{al}^{4}$ described ASO titer status raised 10 times than their control in chronic plaque psoriasis. All these studies showed significant differences ( $p$ value $<$ $0.05)$ with their respective controls. The outcome of above mentioned studies were similar and also supportive for the present study findings.

In case of throat swab culture, in case of total guttate psoriasis (AGP+Guttate flare) Streptococcus pyogenes was presence in $9(30 \%)$ cases and in $2(9.5 \%)$ cases of 
their respective controls ( $\mathrm{p}$ value 0.1 ). Streptococcus pyogenes was isolated from $26 \%$ in AGP, $13 \%$ in guttate flare of chronic plaque psoriasis, $14 \%$ in chronic plaque psoriasis and $6 \%$ in total controls ${ }^{12}$. In another study by Naqqash et $\mathrm{al}^{6}$ isolated Streptococcus pyogenes 34\% in chronic plaque psoriasis and $97 \%$ in AGP. Gudjohnson et $\mathrm{al}^{4}$ showed Streptococcus pyogenes positive in throat swab culture was $9.1 \%$ in chronic plaque psoriasis versus $0.9 \%$ in controls ( $p$ value $<0.05$ ). Among these above mentioned studies showed significant difference in culture results in AGP versus controls. Culture result of this present study were nearly similar with above mentioned others studies findings $s^{4,6,12,15}$. Confirmation of Streptococcal infections in psoriasis may be difficult because patients are often seen in the convalescent phase when antibiotics have already been taken and throat swab culture are more likely to be negative.

Keeping these studies in mind, and the strong association documented in this study, between guttate psoriasis and in terms of evidence of current Streptococcal throat infections evidenced by raised ASO titer and positive throat swab culture, it is important to search for and eliminate microbial infections in the treatment of psoriasis.

\section{Conclusion}

In light of above mentioned results and discussion it can be concluded that this study confirms that Streptococcus pyogenes can cause provocation of gutate psoriasis. More studies are needed with greater numbers of patients, greater number of institutions involvement, so that risk associations of psoriasis can be determined accurately.

\section{References}

1. Griffiths CEM, Camp RDR, Barker JNWN. Psoriasis. Rook"s textbook of dermatology. 7th edition. Masachusetts: Blackwell Publisher; 2004. pp.35-69 2. Neimann AL, Porter SB, Gelfand JM. The epidemiology of psoriasis.
Expert revision of dermatology2006; 1(1): 63-75

3. Terui T, Ozawa M, Tagami H. Role of neutrophils in induction of acute , inflammation in T-cell-mediated immune dermatosis, psoriasis: A neutrophilassociated inflammation-boosting loop. Experimental Dermatology 2000; 9(1):1-10 4. Gudjonsson JE, Thorarisson AM, Sigurgeirsson B, Kristinsson KG, Valdimarsson H. Streptococcal throat infections and exacerbation of chronic plaque psoriasis: a prospective study. British Journal of Dermatology 2003;149:530-534

5. Leung DY, Walsh P, Giorno R, Norris DA. A potential role for superantigens in the pathogenesis of psoriasis. J Invest Dermatol 1993; 100: 225-8

6. Naqqash S, Uddeen Tameez, Naqqash SH, Butt AK. Family history of psoriasis and recent infectious disease are risk factor for the first episode of acute guttate psoriasis. Journal of Pakistan Association of Dermatologists 2004; $14: 124-9$

7. McFadden J, Valdimarsson H, Fry L. Cross-reactivity between streptococcal $M$ surface antigen and human skin. British Journal of Dermatology 1991; 125: 443-447

8. Korotky NG, Peslyak MY. Psoriasis as a consequence of incorporation of beta-Streptococci into the microbiocenosis of highly permeable intestines. Vestn Dermatol Venerol 2005; 1: 9-18

9. Baker BS, Powel AV, Malkani AK. Altered cell-mediated immunity to group A haemolytic streptococcal antigens in chronic plaque psoriasis. British Journal of Dermatology 1991; 125: 38-42

10. Swerlick RA, Cunningham MW, Hall NK. Monoclonal antibodies crossreactive with group A Streptococci and normal and psoriatic human skin. J Invest Dermatol 1986; 87:367-371

11. Villeda GG, Santamaria CLC, Perez LR. Recognition of Streptococcus pyogenes and skin autoantigens in guttate psoriasis. Arch Med Res 1998; 29: 143-8 12. Telfer NR, Chalmers RJG, Whale K, Colman G. The Role of Streptococcal Infection in the Initiation of Guttate Psoriasis. Arch Dermatol1992; 128: 39-42

13. Naldi L, Griffiths CEM. Traditional therapies in the management of moderate to severe chronic plaque psoriasis: an assessment of the benefits and risks. British Journal of Dermatology 2005;152 (4): 597-615

14. Mukherjee SK. Streptococcal infection as trigger for psoriasis. Contemporary Pediatrics 2011; 2(1): 207-215

15. F.M.Kohn, S.Pflieger-Bruss and W.B.Schill. Penile Skin diseases. Andrologia 1999; 31(suppl.1):3-11 